\title{
Qualidade ofertada e demandada: as certificações da qualidade ISO e PGQP em uma instituição de ensino de Pelotas/RS
}

\section{RESUMO}

0 presente estudo tem por objetivo analisar a capacidade de uma instituição de ensino em atender aos requisitos de qualidade esperados por seus clientes, a partir de certificações da qualidade ISO e PGQP. Para isso, foi necessário revisitar teorias e abordagens de qualidade em suas diversas aplicações; em seguida, foi possível o desenvolvimento de um instrumento de coleta de dados com base nas referências propostas. A coleta de dados foi desenvolvida por meio da utilização de entrevistas, e analisada pela técnica de análise de conteúdo. São apresentados os resultados da pesquisa e sugestões de melhorias para a instituição. A realização da pesquisa permitiu verificar uma relação entre a qualidade ofertada e a qualidade esperada; com isso, os requisitos das certificações ISO e PGQP aplicados de forma integrada tornam-se capazes, na instituição pesquisada, de contemplar os requisitos da qualidade dos seus clientes. Em complemento, foi possível indicar que a manutenção de tais certificações proporciona a possibilidade de ampliação do atendimento dos critérios de qualidade esperados por seus clientes.

Palavras-chave: Gestão da qualidade. Qualidade em serviços. Instituição de ensino profissional.

\section{INTRODUÇÃO}

Os avanços tecnológicos, as mudanças comportamentais, socioeconômicas e políticas têm resultado no surgimento de novas formas de gestão. Sistemas de trabalho que foram vigentes, durante anos, atualmente sofrem modificações constantes. Tarefas, estrutura, pessoas, ambiente e tecnologia são variáveis que ganharam ênfase ao longo dos anos nas teorias administrativas. Nesse contexto, a qualidade, a produtividade, a competitividade, o comportamento do consumidor, e a inovação são elementos que, na contemporaneidade, têm identificado o universo do trabalho e o mundo daqueles que se mantêm envolvidos com a prestação de serviços e com a gestão de negócios.

A corporação mantenedora da instituição pesquisada tem por missão educar para o trabalho em atividades de bens, serviços e turismo; tal instituição de ensino possui 64 anos de realização de suas atividades, atuando em todo o estado do Rio Grande do Sul por intermédio de 44 unidades de ensino. A partir de 2003, a instituição começou a reformular as suas práticas de gestão, as quais passaram a ser embasadas na gestão pela qualidade total. Atualmente, o sistema de gestão institucional é certificado pela International Organization for Standardization (ISO) e pelo Programa Gaúcho da Qualidade e Produtividade (PGQP), certificações reconhecidas nacional e internacionalmente na área da qualidade. 
A instituição pesquisada é uma das unidades que compõe essa corporação; por sua vez, é de sua própria responsabilidade a realização das atividades de ensino na cidade de Pelotas/RS e área de abrangência, que é composta pelos municípios de Santana da Boa Vista, Canguçu, Morro Redondo, Capão do Leão, Jaguarão, Arroio Grande, Herval, Pedro Osório, Turuçu, Arroio do Padre e Cerrito. Com base no sistema de gestão institucionalizado pela mantenedora, a unidade pesquisada também gerencia suas atividades com fundamento na Gestão pela Qualidade e é certificada pela ISO e pelo PGQP.

O PGQP é uma certificação da qualidade que visa analisar a gestão de uma instituição; já a ISO tem em vista verificar elementos relacionados aos processos. Contudo, ambas as certificações possuem o objetivo central de certificar se a gestão ou os processos, respectivamente, atendem às necessidades dos clientes das organizações. Assim sendo, toda instituição, independentemente da sua natureza de atividade, possui condições de aderir ao sistema de gestão pela qualidade ISO e PGQP, visto que todas elas são constituídas por processos a serem realizados e atividades a serem gerenciadas.

A análise de alguns indicadores e ferramentas de interação com os clientes, os quais fazem parte do sistema de gestão certificado da unidade, fez com que o seu grupo gestor apontasse para um possível descompasso entre as métricas da qualidade empregadas pelas certificações ISO e PGQP (qualidade ofertada) e os requisitos de qualidade esperados pelos seus clientes (qualidade demandada). Diante disso, tornou-se importante pesquisar a aderência dos elementos da qualidade ofertada pela unidade em relação à qualidade demandada pelos seus clientes.

Cabe ressaltar que a Qualidade Total, como forma de gestão, teve seu ápice no fim dos anos 1980 e início dos 90, desenvolvendo-se até a atualidade, no que tange à administração das organizações. Grande parte dos autores que tratam do tema da Qualidade Total realizaram produções nesse período, e os autores citados neste trabalho estão de acordo com as abordagens vigentes na referida época.

Existem críticas à adoção dessas formas de gestão na Educação, conforme afirma a Organização para a Cooperação e Desenvolvimento Econômico (OCDE): a qualidade no ensino não é uma "mais-valia" que se possa obter mediante um simples esforço pontual, ela deve ser uma prioridade constante.

Para tal instituição, o ensino não pode ser assemelhado a uma linha de montagem, graças à qual se possam aumentar mecanicamente os meios de produção a fim de multiplicar a produtividade. As medidas que permitem melhorar sua qualidade suscitam questões fundamentais sobre os fins que a sociedade atribui ao ensino, sobre a natureza da participação na tomada de decisões em todos os níveis e sobre as próprias finalidades da escola como instituição (OCDE, 1992).

Chama a atenção, entretanto, o fato de que algumas escolas optaram por ir a fundo nessa forma de administração característica dos sistemas de gestão pela qualidade e muito difundida no meio industrial e comercial. Portanto, cabe entender até que ponto as certificações ISO e PGQP representam melhorias para os sistemas de gestão das instituições de ensino e, principalmente, trazem benefícios para os processos educacionais.

É notável que certificações da ISO e PGQP são capazes de gerar melhorias na gestão de empresas industriais e comerciais. Contudo, este artigo busca verificar se a implantação dessas certificações em uma instituição de ensino é capaz de fazer o cliente perceber melhorias na qualidade da organização.

Nesse contexto, o presente trabalho recebe maior relevância, visto que na atualidade as certificações da qualidade ISO e PGQP, mesmo partindo de um enfoque industrial ou comercial, passam a serem adotadas por instituições de ensino como forma de certificação da qualidade. Todavia, torna-se relevante a verificação da capacidade dos elementos abordados pelas certificações, que possuem origem nas indústrias, em aderirem aos processos e formas de gestão em instituições que oferecem serviços educacionais.

Com isso, o estudo em tela é um convite à seguinte reflexão: É possível, por meio de certificações da qualidade, uma instituição de ensino obter a qualidade demandada por seus clientes?

A fim de atender aos requisitos necessários para a realização do presente estudo, os construtos teóricos a respeito da qualidade são revisitados; são abordadas também as características das certificações da qualidade ISO e PGQP, as formas de gestão adotadas por instituições de ensino profissional e, por fim, por meio de uma entrevista com estudantes de uma escola certificada - ISO e PGQP -, busca-se compreender se, de fato, a qualidade certificada pela organização é refletida sob o ponto de vista dos seus clientes.

\subsection{Objetivo geral}

Analisar a capacidade de uma instituição de ensino profissional em atender aos requisitos de qualidade esperados por seus clientes, a partir da obtenção de certificações ISO e PGQP. 


\subsection{Objetivos específicos}

a) Analisar os critérios das certificações da qualidade do PGQP e da ISO.

b) Identificar lacunas, sobreposições e relações entre os elementos das certificações ISO e PGQP.

c) Analisar os elementos da qualidade esperada pelos clientes da instituição pesquisada.

d) Relacionar os elementos das certificações ISO e PGQP com os elementos apontados pelos clientes da instituição.

e) Analisar a aderência das relações entre os elementos das certificações e os esperados pelos clientes.

f) Sugerir melhorias para a instituição pesquisada.

\section{ABORDAGENS VIGENTES DA QUALIDADE}

O sentido do termo qualidade não é muito preciso, e o seu emprego varia de acordo com os interesses em causa (OCDE, 1992). Dessa maneira, o desconhecimento técnico acerca do tema pode ser a fonte das divergências em relação ao emprego do termo.

A qualidade do ensino dá lugar, nas mais diversas circunstâncias, a apreciações mais ou menos precisas, mas os estudos sistemáticos são raros; portanto, as opiniões que lhe dizem respeito nem sempre são fundamentadas, seja qual for o sentido que se lhe atribui (OCDE, 1992).

Segundo Hargreaves, Zuanetti e Lee (2001), essa preocupação com o cliente e a qualidade dos produtos e serviços continuam presentes, mesmo com o passar dos anos. Como as tecnologias evoluem e inovam a produção sistematicamente, e com o ambiente cada vez mais competitivo, surge o cliente mais exigente em relação à qualidade do produto e dos serviços. Existem determinadas definições para qualidade; a seguir, demonstram-se algumas delas. De acordo com Crosby (1984), qualidade significa fazer o que havíamos dito que iríamos fazer, significa dar ao cliente exatamente o que ele pediu, e isso vale para clientes internos e externos.

Já Taguchi, Elsayed e Hsiang (1990) esclarecem que qualidade ocorre quando um produto ou serviço desempenha suas funções sem efeitos colaterais daninhos. Maior qualidade significa desempenhar a mesma função com menos perda para o cliente. Segundo Drucker (1999), qualidade não é algo que o fornecedor coloca num produto ou serviço, mas algo que o cliente obtém e pelo qual paga. Os clientes pagam apenas por aquilo que lhes é útil e lhes traz valor. Nada mais constitui qualidade.

O PGQP (2013a) entende que qualidade é um termo complexo de ser definido, em virtude de diferentes percepções e expectativas do cliente; para isso, a maneira encontrada é a busca da excelência da gestão, tendo em vista que as organizações, quando possuem qualidade em sua gestão, podem atender de maneira mais satisfatória aos seus públicos.

Dessa forma, torna-se evidente a relevância da observação dos requisitos dos clientes no que se refere aos produtos e serviços oferecidos pelas organizações para a definição da qualidade.

Assim sendo, baseando-se nas definições expostas, percebe-se que, apesar de divergentes, existem pontos em comum entre os conceitos, como na funcionalidade do produto ou serviço oferecido ao cliente, no valor que o produto ou o serviço tem para o cliente e na prerrogativa do cliente na definição do que lhe é útil.

Dessa maneira, no presente estudo, qualidade é abordada da seguinte forma: qualidade é a capacidade de oferecer produtos ou serviços que possuam funcionalidade, valor e utilidade de maneira a atender às necessidades do cliente final.

Tal conceito está em conformidade com as definições de Crosby (1984), Taguchi, Elsayed e Hsiang (1990), Drucker (1999), Hargreaves, Zuanetti e Lee (2001), PGQP (2013a), e Cerqueira e Martins (2008).

\section{QUALIDADE EM INSTITUIÇÕES DE ENSINO}

Em referência à qualidade na educação, a OCDE (1992) ressalta que, no domínio do ensino, e quando se lhe atribui um sentido normativo, a palavra qualidade adquire uma importância e um alcance político maiores.

Quando a palavra qualidade significa grau de excelência, ela cobre, por um lado, o valor que decorre essencialmente de um parecer, e, por outro lado, a posição ocupada pelo objeto considerado numa escala implícita que vai do bom ao mau. Se por exemplo, julga-se que a qualidade de uma escola é "boa", "medíocre" ou "excelente", aplica-se-lhe, de forma mais ou menos precisa, um determinado critério de valor e atribuisselhe em simultâneo, e da mesma forma, uma posição, relativamente a outras escolas (OCDE, 1992). 
A análise do conceito de qualidade e as várias interpretações encontradas permitem entender parte da confusão que se faz na sua utilização. No mundo da educação, a respeito das diferentes concepções da qualidade, a OCDE (1992) diz que o termo "qualidade" comporta diferentes significações que são ao mesmo tempo descritivas e normativas; aplicando de forma mais particular ao ensino, o seu sentido varia ainda, e diferentes métodos têm sido adotados para definir e melhorar a qualidade destes.

Tais diferenças são inevitáveis, porquanto esse problema pode ser posto de forma pontual, para a escola ou para a classe, mas também de forma mais geral, quando se considera o sistema de ensino no seu conjunto. Isso não é senão uma consequência da natureza subjetiva do conceito e do difícil debate político acerca dos melhores meios de beneficiar a qualidade (OCDE, 1992).

Com base em Rosa (2008), existe uma clara dificuldade em entender a origem dessa metodologia de gestão (Gestão pela Qualidade Total) e os fundamentos mínimos necessários para se atingir o sucesso com a sua implantação. Diferentes formas de gestão foram implantadas no decorrer dos tempos e muitas tiveram uma vida efêmera.

Sob esse prisma, pode-se dizer que, durante sua louvação, a Qualidade Total era vendida como o meio de sobrevivência de toda organização. Ao final da última década, entretanto, verificou-se que, embora seus enormes benefícios para a administração de qualquer negócio, a Qualidade Total perdeu parte de seu status, sem que seus fundamentos deixassem de ser utilizados (ROSA, 2008).

A respeito do uso da gestão pela Qualidade Total no mundo, Vieira e Carvalho (1999) salientam que gerenciamento da qualidade é uma forma de administração que teve seu início como o sistema de gestão mais difundido no ocidente. Em companhias japonesas, atualmente, é atribuído não somente a sua competitividade por baixos custos de produção, mas também pela alta qualidade e alto grau de confiabilidade conferida a seus produtos em termos gerais.

Com o objetivo de atingir o mesmo grau de competitividade das organizações asiáticas, o gerenciamento da qualidade começou a ganhar crescente importância igualmente nas empresas e organizações em geral, sobretudo em países industrializados. Wilson (1992) lembra que hoje em dia é difícil encontrar uma organização de grande ou médio porte nessas localidades que não tenha implementado o gerenciamento da qualidade em alguma de suas variações ou, em outras palavras, que não tenha institucionalizado algum tipo de abordagem da qualidade em relação a suas atividades.

$\mathrm{Na}$ gestão da Educação também se encontram novas formas de trabalho, mas não com a mesma velocidade de mudança verificada em outros segmentos. A tradição, os valores característicos do mundo educacional, a especificidade do meio acadêmico e a própria resistência à mudança, de boa parte dos educadores, podem ser citados como motivos para a baixa velocidade encontrada na tentativa de implantar novas formas de gestão na Educação (ROSA, 2008).

Segundo Mezomo (1999), a Qualidade Total na educação é necessária e possível. A qualidade não pode ser um simples desejo e sim uma forma de pensar; é necessário refletir e repensar em todos os processos; esse repensar deve iniciar pelos planejadores, idealizadores e gestores. "A qualidade na educação é um trabalho de todos e de cada um" (MEZOMO, 1999, p. 178).

Em consonância com Mezomo (1999), Spanbauer (1995) explica que as técnicas e os processos da qualidade e produtividade podem ser transferidos com sucesso para a educação; os modelos de empresas podem ser usados no desenho curricular, horários e fornecimento da educação; os processos da qualidade podem melhorar a gerência e a operação de instituições educacionais e, simultaneamente, melhorar o ambiente de aprendizado e a realização dos alunos.

Apesar de a OCDE (1992) indicar restrições à aplicação do sistema de qualidade total em instituições de ensino, autores como Wilson (1992), Vieira e Carvalho (1999), e Rosa (2008) afirmam que sistema de gestão pela qualidade pode e deve ser aplicado a qualquer instituição, independentemente da atividade realizada. Em complemento, Spanbauer (1995) e Mezomo (1999) indicam uma série de possibilidades de melhorias com a aplicação da gestão da qualidade total em instituições de ensino; algumas dessas melhorias são na gerência de instituições educacionais e no ambiente de aprendizado (SPANBAUER, 1995), e nos processos e no planejamento (MEZOMO, 1999).

\section{ORGANIZAÇÃO INTERNACIONAL PARA PADRONIZAÇÃO}

De acordo com Rosa (2008), o sistema de gestão baseado na qualidade valoriza a questão da padronização, assim como as certificações de qualidade que sejam reconhecidas e aceitas por todas as empresas. Nesse aspecto, o autor ressalta a ISO como forma de atestar a adequabilidade aos requisitos das normas e auxiliar na padronização de processos e de probabilidades internacionais. 
A ISO é uma organização não governamental, com sede em Genebra, na Suíça. A sua missão é promover o desenvolvimento de normas voluntárias no mundo, facilitando o comércio de produtos e serviços, e o desenvolvimento da cooperação de atividades nos campos intelectual, científico, tecnológico e econômico (FUNEP, 2012).

Diversos países aderem a ISO como padrão de certificação da qualidade. Existem cerca de 180 comitês técnicos, com representantes desses diferentes países trabalhando na elaboração das normas; o Brasil também faz parte, por meio da Associação Brasileira de Normas Técnicas (ABNT). Nesses comitês há representantes de diversos segmentos e empresas do mercado brasileiro (CERQUEIRA; MARTINS, 2008).

A norma utilizada pelo gerenciamento e garantia da qualidade é a ISO 9001, a qual possui vinte elementos básicos a serem verificados, iniciando pela análise da responsabilidade da administração, que deve buscar uma política da qualidade bem definida, documentada, comunicada, implementada e mantida. Para isso, a norma preconiza a necessidade da existência de um sistema da qualidade documentado, na forma de manual, e implementado a todos os processos da empresa (CERQUEIRA; MARTINS, 2008).

A mesma norma afirma que devem existir requisitos contratuais que precisam ser completos e definidos, sendo de responsabilidade da empresa assegurar que haja todos os recursos necessários para atender à exigência.

De acordo com Cerqueira e Martins (2008), todas as atividades referentes a projetos (planejamento, métodos para revisão, mudanças, verificações e outros) devem ser documentadas; há necessidade da existência de um controle de documentação para propiciar o controle de geração, distribuição, mudança e revisão em todos os documentos. Quando da aquisição de um produto, de acordo com a norma, deve-se garantir que as matérias-primas atendam às exigências especificadas e os fornecedores sejam avaliados; já quanto aos produtos fornecidos para o cliente, é necessário que existam padrões que garantam que estejam adequados para o uso; todos os produtos, por sua vez, devem ser identificados e rastreados, requerendo identificação por item, série ou lote durante os estágios de produção, entrega e instalação.

Quanto aos processos, com base em Cerqueira e Martins (2008), a certificação ISO requer que todas as fases de processamento de um produto sejam controladas por procedimentos, normas ou manuais, e documentadas; toda matéria-prima, antes da utilização, deverá ser inspecionada; para isso, os equipamentos para inspeção deverão estar calibrados/aferidos. Após a inspeção, os produtos devem possuir identificadores de sua aprovação (ou não) na inspeção.

Quando não forem atendidos os requisitos mínimos na inspeção, deverá existir um controle dos produtos não conformes, impedindo a sua utilização. 0 critério também exige que a empresa possua ações corretivas quando exista uma não conformidade e qual a ação para não ser reincidente. Para que seja verificado se tudo está em conformidade, é indispensável que sejam feitas auditorias internas que, baseadas nos registros da qualidade, verificarão e implantarão o sistema de avaliação do programa; são exigidos treinamentos para os funcionários a fim de obterem conhecimentos e habilidades nas suas funções.

\section{PROGRAMA GAÚCHO DA QUALIDADE E PRODUTIVIDADE}

Segundo o Programa Gaúcho da Qualidade e Produtividade (PGQP) (2013a), o programa é liderado pelos empresários gaúchos Jorge Gerdau Johanpeter e Ricardo Felizzola. O Programa Gaúcho da Qualidade e Produtividade atua há vinte anos na promoção da competitividade do Rio Grande do Sul para melhoria da qualidade de vida dos cidadãos, nos setores público, privado e terceiro setor. Foi criado em 1992 e gerido pelo setor público (governo do Estado do Rio Grande do Sul) até 1998, quando, posteriormente, se tornou uma entidade comunitária.

Com a missão de promover a competitividade no estado rio-grandense e com o apoio político e participação de líderes empresários, o PGQP é considerado um dos maiores patrimônios gaúchos na disseminação da qualidade e melhoria de gestão das organizações, servindo de referência e motivação para outros estados. O PGQP está distribuído no estado por intermédio de oitenta comitês setoriais e regionais (PGQP, 2013a).

Para propiciar busca pela excelência em Gestão, o PGQP enfatiza a utilização do Sistema de Avaliação da Gestão (SAG) - um instrumento de diagnóstico organizacional destinado a organizações que possuem um sistema de gestão. Os critérios de avaliação compõem a metodologia do PGQP, proporcionando diagnosticar o estágio de desenvolvimento, gerenciar e planejar ações visando à melhoria contínua.

O SAG, por sua vez, utiliza-se do Modelo de Excelência da Gestão (MEG), abordado pelo PGQP, que reflete a experiência, o conhecimento e o trabalho de pesquisa de diversas organizações especialistas no Brasil. 0 MEG é baseado em onze fundamentos da excelência e colocado em prática por oito critérios. Os Critérios 
de Avaliação são representados pela Figura 1, que simboliza a organização, considerada como um sistema orgânico que interage com o ambiente.

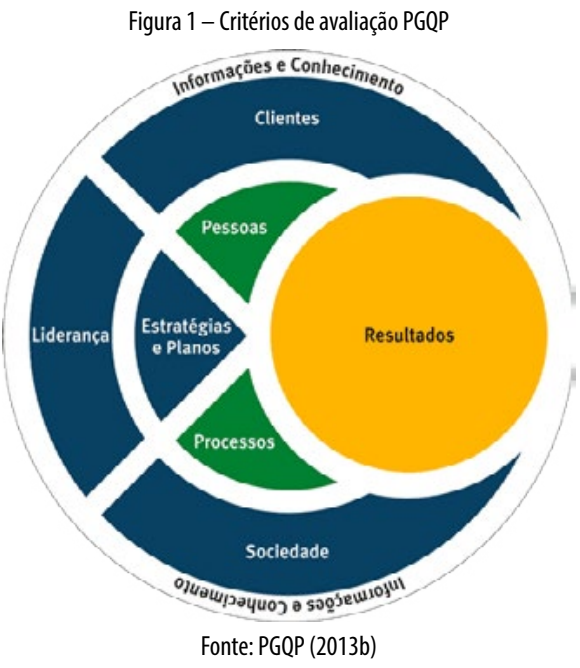

Mesmo a Figura 1 permitindo diferentes interpretações e percepções por parte dos envolvidos, de acordo com o PGQP (2013), esse modelo baseia-se na noção de aprendizado conforme o ciclo PDCL (Plan, Do, Check, Learn), conhecido também como ciclo de Shewhart ou ciclo de Deming. Conforme o PGQP (2013b), o sucesso das organizações está relacionado à capacidade de atender às expectativas e necessidades dos clientes, as quais devem servir de inputs (Entradas) para o desenvolvimento dos produtos, criando valor necessário para conquistá-los e retê-los. Ainda de acordo com o PGQP (2013b), para que exista continuidade nas operações, a sociedade e as comunidades igualmente devem ser ouvidas, e a organização deve atuar de forma responsável, contribuindo para o desenvolvimento socioambiental.

No que diz respeito à liderança, o PGQP (2013b) esclarece que devem ser fornecidas informações sobre os princípios da organização, as práticas e vivências dos fundamentos da excelência, assim impulsionando a cultura da excelência da organização. Tais elementos são considerados os principais responsáveis para obtenção de resultados que garantam a satisfação das partes interessadas, permitindo que a organização mantenha-se no mercado analisando o desempenho de suas ações e, sempre que preciso, buscando o aprendizado organizacional.

Segundo o PGQP (2013b), as estratégias são formuladas pelos líderes a fim de dar o norte à organização, buscando o desempenho e determinando a posição competitiva. Inicialmente são estabelecidas metas pertinentes e referenciais; depois estratégias são desdobradas em planos de ação de curto e longo prazo; em sequência, as estratégias, metas e planos são comunicados às pessoas da força do trabalho e, quando necessário, às demais partes interessadas. Cabe ressaltar que esses quatro critérios descritos até o momento representam a etapa Planejamento (P) do ciclo PDCL da organização, seguido pelo PGQP.

No que se relaciona às pessoas da força de trabalho, o PGQP (2013b) lembra que elas devem estar capacitadas e comprometidas com a organização, atuando em um ambiente propício para a execução de suas atividades e o gerenciamento dos processos; dessa forma, criando valor aos clientes e aperfeiçoando o relacionamento com os fornecedores. Com isso, atendendo a etapa de Fazer (D) do PDCL.

Por meio dos resultados obtidos e dos efeitos gerados das situações econômico-financeiras, clientes e mercado, pessoas, sociedade, processos e fornecedores, é possível realizar uma comparação com as metas estabelecidas como referenciais para cada elemento. E, assim, estar de acordo com a etapa de Controle (C) do PDCL.

Os resultados obtidos pela organização, como os referentes à informação e conhecimento, são remetidos novamente à organização (Feedback) para que sejam possíveis executar ações necessárias em todos os níveis organizacionais. E, com isso, atendendo à etapa Aprendizado (L) do PDCL.

Os oito critérios demonstrados são divididos em requisitos específicos, os quais recebem uma pontuação, de acordo com o atendimento da organização a cada item. Para a confecção do relatório de avaliação do PGQP, o ponto de partida é o levantamento do Perfil da Organização; trata-se de uma apresentação geral, com as principais características da organização que será avaliada. A seguir são descritos o sistema de gestão (com base nos critérios demonstrados anteriormente e foco no PDCL) e os resultados obtidos pela organização 
em cada critério de avaliação.

\section{SOBREPOSIÇÕES, LACUNAS E RELAÇÕES ENTRE AS CERTIFICAÇÕES ISO E PGQP}

Com base na análise e comparação entre elementos da ISO e PGQP, é notável a existência de sobreposições, lacunas e relações entre as abordagens empregadas por ambos. Assim sendo, torna-se possível a proposta de uma reunião entre os elementos das certificações, respeitando-se as bases e os enfoques de cada uma, como forma de simplificação para abordá-las conjuntamente.

Existem alguns elementos que visam à análise ou verificação de dados e informações em comum entre as certificações, ou seja, proporcionam a análise de itens aplicando o mesmo enfoque e com o intuito de atender ao mesmo objetivo. São eles: liderança, responsabilidade da administração, estratégias e planos, sistema de qualidade: controle de documentos; registro da qualidade e auditorias internas da qualidade, clientes, produtos fornecidos pelo cliente, pessoas, treinamento, processos e análise crítica de contratos; controle de projetos; aquisição; identificação e rastreabilidade do produto; controle de processos; manuseio e armazenamento; embalagem e expedição.

0 PGQP enfoca o elemento Liderança e as formas em que a liderança torna-se capaz de agir sobre a organização, de acordo com uma visão sistêmica e com base na qualidade; já a ISO, com o mesmo intuito, caracteriza esse elemento como Responsabilidade da Administração. Isso demonstra que os dois programas preocupam-se com a visão da liderança a respeito do conjunto da organização; dessa forma, a fim de propor uma estrutura combinada entre as certificações, reúnem-se os elementos dos referidos critérios sob o rótulo de Responsabilidades da Liderança.

Pensando em como a liderança executaria suas atividades, com o foco na qualidade, para o alcance dos resultados, o PGQP possui os elementos Estratégias e planos; da mesma forma, a ISO apresenta como elementos Sistema de qualidade: Controle de documentos, Registro da qualidade e Auditorias internas da qualidade; todos eles visam demonstrar a forma que a organização, com foco na qualidade, pode alcançar os objetivos; para a reunião de tais elementos, propõe-se a nomenclatura de Estratégia, planos e qualidade.

O cliente, de acordo com o PGQP, é uma entrada de demandas e uma saída de produtos. É importante conhecê-lo, pois é para ele que está sendo oferecido o que se produz, sendo assim o responsável para o funcionamento da organização. A ISO, da mesma forma, considera o cliente como foco na análise do elemento Produtos fornecidos pelo cliente, que é o momento em que verifica se realmente está atendendo ao que o cliente deseja, isto é, foco na qualidade para o cliente; desse modo, propõe-se a nomenclatura de cliente para a referida reunião de critérios.

Para atingir os objetivos e o alcance das estratégias, por meio dos processos, o PGQP entende que as pessoas são os motivadores que fazem a organização funcionar, para isso, a organização deve se preocupar com os colaboradores, pois, de acordo com o PGQP (2013b), são eles que fazem a organização. Conforme a ISO, a única preocupação relativamente a colaboradores é com o treinamento, a fim de que o colaborador esteja preparado para atuar naquela função. Apesar de tal divergência, é possível estabelecer relações entre tais critérios, visto que possuem elementos similares; com isso, rotula-se a proposta de reunião de critérios sob a identificação de Pessoas.

O PGQP busca analisar de que forma são conduzidos e gerenciados os processos a fim de gerar valor para os clientes; esses processos são de execução dos produtos e atividades, que vão desde a análise dos fornecedores até a análise econômico-financeira da organização; já a ISO busca dentre seus elementos: Análise crítica de contratos, Controle de projetos, Aquisição, Identificação e rastreabilidade do produto, Controle de processos, Manuseio e armazenamento, Embalagem e expedição, identificar de que forma a organização está preocupada em operar seus processos a fim de atender às demandas. Assim sendo, é possível propor uma reunião das abordagens sob a nomenclatura de Controle dos processos.

Por outro lado, alguns critérios não possuem relações possíveis de ser realizadas; isso decorre do fato de que as certificações aplicam aos mesmos enfoques e objetivos de análise divergentes, são eles: Sociedade, Inspeção e ensaios, Equipamentos de inspeção, Medição e ensaio, Situação da inspeção e ensaios, Controle de produtos não conforme e ação corretiva e Assistência técnica e técnicas estatísticas.

Para o PGQP, a sociedade possui relevância de análise, pois ela representa a comunidade onde a organização está inserida. De acordo com esse critério, deverá haver uma preocupação da organização no que tange a como a comunidade vizinha poderá se desenvolver e não ser afetada, de maneira negativa, pelas atividades organizacionais que ali serão realizadas. A ISO não demonstra em nenhum de seus elementos intenções de verificação no que se relaciona às comunidades vizinhas.

A forma de disseminação de conhecimentos dentro da organização é considerada pelo PGQP como um elemento relevante da qualidade, pois de acordo com o PGQP (2013b) é necessário que as informações e conhecimentos adquiridos pela organização sejam disseminados a todos os que participam das atividades 
realizadas por ela; a ISO não expõe em nenhum de seus elementos a preocupação relativamente aos conhecimentos e informações da organização.

O PGQP considera que todos esses elementos possuem a finalidade de buscar resultados consistentes e comparáveis com o mercado; esses resultados são relacionados a todos os critérios da certificação, ou seja, clientes, sociedade, financeiros, pessoas, processos e fornecedores. Já a ISO não demonstra, de forma direta, em seus elementos, essa atenção relacionada aos resultados.

A ISO, dentre seus elementos, Inspeção e ensaios, Equipamentos de inspeção, Medição e ensaio, Situação da inspeção e ensaios, Controle de produtos não conforme e Ação corretiva, apresenta a indagação quanto ao controle quantitativo (medição) dos produtos e equipamentos utilizados; esse foco deve-se à importância do oferecimento dos produtos da maneira mais exata possível, para não ocorrer o risco da existência de falhas na entrega do produto. O PGQP não apresenta essa preocupação dentro de seus critérios. Com o escopo de reunir esses elementos, propõe-se o rótulo Inspeções e medições.

Com a preocupação de rastreabilidade e confirmação de que o produto seja entregue da melhor forma, a ISO possui o elemento Assistência técnica e técnicas estatísticas, que serve como garantia para o atendimento dos requisitos e garantia do que está sendo oferecido. O PGQP, dentro de seus elementos, não analisa essa questão, possuindo o foco mais no que está sendo oferecido. Com isso, de acordo com a reunião estabelecida, a nomenclatura proposta é Assistência técnica. 0 Quadro 1 demonstra as sobreposições, lacunas e relações expostas no decorrer do presente item do estudo.

Quadro 1 - Sobreposições, lacunas e relações dos elementos PGQP e ISO

\begin{tabular}{|c|c|c|}
\hline Elementos & PGQP & ISO \\
\hline Responsabilidade da Liderança & $X$ & $X$ \\
\hline Estratégia, Planos e Qualidade & $X$ & $X$ \\
\hline Cliente & $X$ & \\
\hline Sociedade & $X$ & $X$ \\
\hline Informação e Conhecimento & $X$ & $X$ \\
\hline Pessoas & $X$ & $X$ \\
\hline Controle dos Processos & $X$ & $X$ \\
\hline Resultados & $X$ & \\
\hline Inspeções e Medições & & $X$ \\
\hline Assistência Técnica & & $X$ \\
\hline
\end{tabular}

Fonte: Os autores (2014)

Demonstra-se no Quadro 2 uma estrutura e análise combinada entre os critérios do PGQP e da ISO. 


\begin{tabular}{|c|c|c|}
\hline Dimensão & Elementos & Fonte \\
\hline \multirow{2}{*}{ Responsabilidade da liderança } & Liderança & PGQP \\
\hline & Responsabilidade da administração & ISO \\
\hline \multirow{5}{*}{ Estratégia, planos e qualidade } & Estratégias e planos & PGQP \\
\hline & Sistema de qualidade & IsO \\
\hline & Registro da qualidade & ISO \\
\hline & Auditorias internas da qualidade & ISO \\
\hline & Controle de documentos & IsO \\
\hline \multirow{2}{*}{ Cliente } & Clientes & PGQP \\
\hline & Produto fornecido pelo cliente & ISO \\
\hline Sociedade & Sociedade & PGQP \\
\hline Informação e conhecimento & Informação e conhecimento & PGQP \\
\hline \multirow{2}{*}{ Pessoas } & Pessoas & PGQP \\
\hline & Treinamento & ISO \\
\hline \multirow{7}{*}{ Controle dos processos } & Processos & PGQP \\
\hline & Análise crítica de contratos & ISO \\
\hline & Controle de projetos & ISO \\
\hline & Aquisição & ISO \\
\hline & Identificação e rastreabilidade do produto & ISO \\
\hline & Controle de processos & IsO \\
\hline & $\begin{array}{c}\text { Manuseio, armazenamento, embalagem e } \\
\text { expedição }\end{array}$ & ISO \\
\hline Resultados & Resultados & PGQP \\
\hline \multirow{3}{*}{ Inspeções e medições } & Equipamentos de inspeção, medição e ensaios & ISO \\
\hline & Controle de produtos não conformes & ISO \\
\hline & Ação corretiva & ISO \\
\hline \multirow{2}{*}{ Assistência técnica } & Assistência técnica & ISO \\
\hline & Técnicas estatísticas & ISO \\
\hline
\end{tabular}

Fonte: 0 s autores (2014)

A relevância da proposta da estrutura anterior refere-se à capacidade de compreensão dos clientes a respeito dos elementos da qualidade oferecidos pela instituição. Posteriormente, a estrutura proposta é aplicada como forma de verificar com os clientes a aderência dos elementos abordados às suas expectativas.

\section{METODOLOGIA}

Este item visa demonstrar o método utilizado neste estudo. Inicialmente, é abordada a caracterização da pesquisa e, na sequência, é apresentado o detalhamento das etapas desenvolvidas.

Com a finalidade de atender aos objetivos propostos, o presente estudo utiliza-se do delineamento de pesquisa exploratória, tendo em vista que, conforme Sampieri, Collado e Lucio (2006), a pesquisa exploratória é utilizada quando os objetivos do estudo propõem a observação do tema com base em novas perspectivas e na ampliação dos estudos já existentes.

A unidade de análise deste estudo são os critérios da qualidade oferecidos pela instituição, baseados na ISO e no PGQP. Em face da unidade de análise abordada, optou-se por um estudo de corte transversal. As entrevistas são as principais fontes de informação do estudo, pois se trata de percepção das pessoas a propósito do tema proposto. 
Os respondentes foram escolhidos de forma aleatória, observando-se a área/modalidade de cursos (serviço oferecido) mais relevante para a organização, para que assim fosse possível ter dados menos tendenciosos, pesquisando diferentes visões devido aos perfis de alunos e sendo abrangente quanto à escolha.

0 perfil dos entrevistados foi selecionado com o intuito de representar o público atingido pela instituição; dentre os entrevistados, a faixa etária é de 17 a 30 anos, a escolaridade é ensino médio e técnico, e o tempo que os entrevistados estão convivendo na escola estudada é de quatro meses a dois anos. Foram realizadas entrevistas em profundidade, de forma direta e pessoal, na Instituição de ensino em questão, as quais tiveram duração média de 45 minutos.

É relevante considerar que o presente trabalho visa à análise das formas de influência dos elementos reunidos do PGQP e da ISO, perante o entendimento e percepção dos estudantes quanto à qualidade desejada em uma instituição de ensino.

Para análise dos dados coletados, foi utilizado o método de Análise de Conteúdo. De acordo com o Bardin (1979), a análise de conteúdo é um conjunto de técnicas de análises das comunicações visando obter, por procedimentos sistemáticos e objetivos de descrição do conteúdo das mensagens, indicadores que permitam a interferência de conhecimentos relativos às condições dessas mensagens. Assim, as percepções dos estudantes pesquisados foram analisadas conjuntamente por similaridade nas respostas. Foi feita uma síntese dos dados obtidos nas entrevistas, agrupando ideias concordantes.

\section{ANÁLISE DOS RESULTADOS}

Neste item são apresentados os resultados obtidos na pesquisa, devidamente interpretados e analisados. (I) Primeiramente é apresentada a empresa na qual foi desenvolvida a pesquisa deste trabalho, sendo abordados, dentre os temas: sua caracterização, últimos resultados e histórico da qualidade. (II) Posteriormente são apresentados os resultados obtidos com base nas respostas dos treze entrevistados.

A instituição pesquisada é uma organização de educação profissional, de direito privado, sem fins lucrativos, que faz parte de uma federação do Rio Grande do Sul. Tal federação representa mais de quinhentas mil empresas do comércio de bens, serviços e turismo no estado gaúcho. A corporação mantenedora da instituição pesquisada, que faz parte dessa federação, caracteriza-se como uma entidade paraestatal (serviço social autônomo), composta pelo Conselho Regional, Administração Regional e Unidades Educacionais; seu objetivo é promover a formação e capacitação para o trabalho, nos níveis de Formação Inicial e Continuada e Educação Profissional Técnica de Nível Médio.

A instituição pesquisada iniciou suas atividades em 15 de fevereiro de 1968 e tem por finalidade a promoção da Educação Profissional e Ações Extensivas à Educação Profissional. Dentro de sua autonomia de atuação, definiu desenvolver ações nos seguintes eixos tecnológicos: Gestão e Negócios, Informação e Comunicação, Produção Cultural e Design, Ambiente, Saúde e Segurança e Hospitalidade e Lazer. Atendendo a doze municípios, considerando sua área de abrangência (Pelotas, Arroio Grande, Jaguarão, Pedro Osório, Cerrito, Herval, Canguçu, Santana da Boa Vista, Morro Redondo, Arroio do Padre, Capão do Leão e Turuçu), tem sob sua administração um campus avançado na cidade de Jaguarão, abrangendo os municípios de Arroio Grande e Herval. Em 2012, realizou em média 9.400 atendimentos; já em 2013, foram em torno de 11.500 atendimentos com 85 colaboradores, sendo trinta deles no setor administrativo e 55 docentes.

Na busca pela excelência, de 2004 a 2008, a instituição participou no sistema de avaliação do PGQP - autoavaliação; em 2009, capacitou quatro colaboradores como Avaliadores e Examinadores do PGQP e um auditor para ISO. Em 2010, a unidade foi vencedora do Troféu Bronze do PGQP e certificada com a ISO; em 2011, foi vencedora do Troféu Prata do PGQP. Em 2012, participou do Sistema de Avaliação, não conquistando nenhum prêmio; em 2013, obteve o Troféu Prata do PGQP e participou da visita da ISO. Em 2014, está buscando a recertificação da ISO e o Troféu Ouro do PGQP.

Em observação aos objetivos da pesquisa, inicialmente, procurou-se identificar a forma como o tema Qualidade era tratado pelos entrevistados. Assim sendo, foi questionada aos participantes a maneira como cada um compreendia a qualidade em uma instituição de ensino. Cabe ressaltar que referida questão foi aplicada visando alinhar possíveis discrepâncias no conceito de qualidade abordado pelos entrevistados em relação ao conceito abordado na pesquisa.

Os entrevistados 1, 2, 3 e 8 entendem a qualidade em uma instituição de ensino como uma forma de atender de forma satisfatória e benéfica às expectativas e necessidades dos clientes, utilizando de modo eficiente os recursos disponíveis, tal como abordado na presente pesquisa.

Os demais entrevistados - 4, 5, 6, 7, 9, 10,11, 12 e 13 - consideram que a qualidade, em uma instituição 
de ensino, é oferecer bem-estar e comodidade ao cliente, focando os esforços para a estrutura, como limpeza dos ambientes, climatização, conforto e ações pedagógicas, como o acompanhamento do docente e seu planejamento de aula.

Os entrevistados 6 e 7 acrescentam que a qualidade em âmbito de uma instituição de ensino deve abranger a preocupação com o atendimento da metodologia de aula, a fim de preparar os estudantes para estarem aptos para o mercado de trabalho.

De acordo com as abordagens dos entrevistados, é possível perceber uma divergência da maioria deles em relação ao conceito básico da qualidade empregada no estudo. Tal resultado era esperado tendo em vista a complexidade do tema abordado, assim como a abstração necessária para a compreensão deste, tal como proposto por OCDE (1992).

Em continuidade ao roteiro de pesquisa proposto, os entrevistados foram questionados a respeito dos elementos que constituem a qualidade de acordo com a percepção de cada um; ressalta-se que tal como a primeira questão, as repostas foram constituídas de maneira espontânea pelos entrevistados.

Os entrevistados 7, 8, 10 e 12 consideram como elementos fundamentais da qualidade em uma instituição de ensino o comprometimento, a capacitação e a competência dos colaboradores para a realização dos processos da escola, assim como um atendimento transparente e cordial. Já para os entrevistados 1, 2, 3, $4,5,6,9,11$ e 13, o foco de elementos considerados como qualidade são os vinculados à estrutura da escola, como limpeza, conforto, organização e climatização.

É possível perceber, com base nas respostas, que a preocupação quanto à qualidade, de acordo com os clientes da instituição, reflete-se diretamente no ambiente escolar no qual eles estão inseridos; esse fato demonstra que os clientes da instituição possuem preocupações latentes com os aspectos visíveis com os quais convivem diariamente.

Os elementos indicados pelos entrevistados estão de acordo com os elementos possíveis de perceberem melhorias com o emprego da gestão pela qualidade total em instituições de ensino, tal como exposto por Mezomo (1999) e Spanbauer (1995). Assim sendo, é relevante verificar que os aspectos demonstrados pelos entrevistados possuem relação com o emprego na gestão pela qualidade total em instituições de ensino.

A verificação a respeito da qualidade, com base nas abordagens empregadas, e a reunião dos elementos da ISO e do PGQP, tal como proposto neste estudo, são consideradas para a análise por parte dos clientes da instituição a seguir.

A primeira dimensão de análise é Responsabilidade da liderança. Os treze entrevistados consideram que tal dimensão causa influência na qualidade, pois justificam que são necessários líderes capazes de gerenciar as ações de acordo com a estratégia empregada pela instituição. Tal abordagem pode ser confirmada na observação do entrevistado 2 que considera que "toda instituição necessita de um bom líder com bom planejamento"; ou de acordo com o entrevistado 7, que justifica que "a liderança deve proporcionar para os colaboradores recursos para desempenhar o melhor papel, é a liderança que estabelece metas e objetivos a serem seguidos".

As respostas dos entrevistados estão de acordo com a dimensão analisada, visto que esta, com base no (I) PGQP (2013b), tem por escopo a preocupação com questões sistêmicas de incumbência dos líderes da organização, e (II) de acordo com Cerqueira e Martins (2008), quando a certificação ISO afirma suas preocupações voltadas para a responsabilidade dos gestores da organização.

A segunda dimensão proposta é Estratégia, planos e qualidade, considerada pelos treze entrevistados como um elemento de influência no que concerne à qualidade de uma instituição de ensino, pois, assim como o entrevistado 7 descreve, "sem estratégia, planos ou objetivos, não se possui um norte nem um caminho a seguir, seria impossível alcançar a qualidade sem traçar um objetivo e uma estratégia para atingi-lo"; o entrevistado 13, em conformidade, afirma que, "com planos e metas bem estipulados, tudo tende a crescer e se desenvolver muito melhor".

As respostas dos entrevistados estão de acordo com a dimensão analisada, visto que esta, com base no (I) PGQP (2013b), tem por finalidade a preocupação de criar planos e controles, para executarem o planejamento alinhado à estratégia do que a organização busca; e (II) da ISO quando a certificação afirma suas preocupações voltadas à manutenção e continuidade de processos da qualidade, a fim de garantir um sistema de gestão voltado para a qualidade e estratégia da organização.

A terceira dimensão, Cliente, é descrita pelo entrevistado 2 como influenciável na qualidade, pois, segundo ele, o mercado ou a organização, a fim de obter o sucesso que necessita, deve entender às necessidades e expectativas de seu público. Diferentemente ao entrevistado 2 e na mesma linha seguida pelos demais, 0 entrevistado 7 considera que nem sempre o cliente sabe o que está buscando, como qualidade, e por tal motivo considera que esse elemento não é capaz de influenciar a qualidade de uma instituição de ensino.

O PGQP (2013b) considera que os clientes são fonte de entrada de demanda e saída de produtos; logo, 
devem ser levados em consideração para a busca e alinhamento para o oferecimento do serviço e a qualidade nele empregada; da mesma forma a ISO (2008) considera que o produto fornecido pelo cliente deve estar conforme suas necessidades e expectativas; isso demonstra que os respondentes estão alinhados a tal visão, com exceção do entrevistado 7 que considera que a dimensão Clientes não é relevante para a qualidade da instituição.

0 isolado posicionamento do entrevistado 7 indica que, para ele, o cliente nem sempre é capaz de determinar a qualidade de uma organização e, por esse motivo, deve ser desconsiderado em uma avaliação da qualidade; ressalva-se que, para os demais entrevistados, conforme já demonstrado, referido elemento possui grande relevância para a qualidade de uma instituição de ensino.

A quarta dimensão é Sociedade; todos os entrevistados consideram que tal critério é capaz de influenciar a qualidade; o entrevistado 13 vai além e salienta que "a sociedade contribui com o desenvolvimento da escola; se a escola considera as necessidades da sociedade ela só vai ter ganhos". Da mesma forma, alguns entrevistados consideram que a mencionada dimensão pode ser utilizada como forma de divulgação e para gerar um bom relacionamento da escola com a comunidade do entorno. Segundo os entrevistados, o objetivo da observação da citada dimensão é a atuação voluntária, a fim de propiciar o desenvolvimento mútuo.

Tal dimensão é oriunda unicamente dos elementos da qualidade do PGQP (2013b), que considera que deve haver uma preocupação da organização em relação à comunidade vizinha, para desenvolvê-la e não afetá-la de maneira negativa pelos impactos ambientais e sociais. Assim, verifica-se que as considerações dos entrevistados estão de acordo com a dimensão sociedade da estrutura de análise combinada do PGQP e ISO. A ISO, tal como abordado por Cerqueira e Martins (2008), não compreende elementos nessa dimensão.

A próxima dimensão é Informação e conhecimento. Os entrevistados 1 e 6 não consideram como uma dimensão capaz de influenciar a qualidade; para eles, os conhecimentos adquiridos são do colaborador e não precisam ser repassados; os entrevistados acreditam que cada um é detentor da sua informação, não sendo necessária a troca e disseminação dentro da organização.

A abordagem dos entrevistados 1 e 6 diverge fortemente da maioria, que acredita que a mencionada dimensão é de grande relevância, pois consideram que a organização deve evidenciar da melhor forma as sistemáticas de obtenção e disseminação de informações, para que assim possam ser compartilhados os objetivos, metas, métodos e outras questões. Posicionamento que está de acordo com elementos abordados na estrutura de análise proposta.

Na dimensão Pessoas, o entrevistado 8 defende que ela só causa interferência na qualidade a partir do momento em que a pessoa desenvolve uma função que mantenha contato com o aluno; já os demais entrevistados acreditam que deve existir uma preocupação em relação ao reconhecimento, qualidade de vida e treinamentos, conforme descritos por Cerqueira e Martins (2008) e PGQP (2013b), a fim de manter os colaboradores motivados e, desse modo, executarem de forma satisfatória os processos, atendendo, assim, a organização de forma sistêmica, permitindo que esta obtenha maiores níveis de qualidade.

Os entrevistados consideram que a dimensão Controle de processos influencia a qualidade sob o enfoque da prestação de serviço. De acordo com eles, é necessário o controle e acompanhamento de todos os processos, pois sem referido controle não há como saber se a organização está alcançando seus objetivos ou prestando atendimentos dentro dos padrões. De acordo com o entrevistado 1, "é importante para, caso ocorra algum tipo de erro, possa saber onde e por que ocorreu este erro, assim prevenindo para que o mesmo não volte a ocorrer novamente".

Segundo o PGQP (2013b), é necessário verificar e acompanhar todo o processo executado na escola para obter um melhor monitoramento de sua execução; conforme Cerqueira e Martins (2008), a dimensão reflete-se em como a organização opera seus processos a fim de atender às demandas; isso demonstra que os entrevistados estão em consonância ao proposto.

As estratégias e planos da organização, como categorias de análise, devem, segundo a maioria dos entrevistados e do PGQP (2013b), ser mensurados a fim de ser controlados; esse controle pode ocorrer por meio dos Resultados (considerado na reunião de elementos proposta). 0 entrevistado 11, de maneira divergente, não acredita que isso seja relevante; segundo ele, a mensuração dos resultados não interfere na qualidade daquilo que está sendo oferecido, a preocupação deve ser no que é oferecido e não no quanto isso é válido em números. 0 entrevistado 13 ressalta que, quanto maior for o resultado, maior será o nível de ensino e a credibilidade da instituição no mercado.

Quanto à nona dimensão, que se refere a Inspeções e medições, todos os entrevistados a consideram como influenciável para a qualidade; de maneira transversal às repostas, percebe-se que é necessário que a organização, por tempos alternados, seja capaz de verificar o serviço prestado e atenda pelo menos a algumas normas de padronização. Essa mesma percepção está descrita nos elementos propostos pela ISO (2008). 
A última dimensão leva em consideração a Assistência técnica; os entrevistados entendem que é uma dimensão que possui relevância no contexto proposto, pois, conforme eles e Cerqueira e Martins (2008), mesmo com o controle do processo e as inspeções realizadas durante o andamento da prestação do serviço, após o final da relação direta da instituição com o cliente, se, em algum momento, o serviço que foi prestado está fora do padrão, deve existir um acompanhamento e ser oferecido novamente o serviço que foi afetado ou está fora do padrão. 0 entrevistado 1 justifica informando que, caso ocorra uma insatisfação do cliente, pelos padrões mínimos não terem sido atendidos, é de extrema importância o cliente ser amparado. Isso se torna necessário para recuperar a credibilidade da instituição com o cliente.

Após a verificação das dimensões propostas e da influência de cada uma na qualidade, a última questão do roteiro da entrevista visou à ampliação da abordagem empregada, questionando ao entrevistado a respeito da existência de algum elemento de análise que não tenha sido considerado nas questões anteriores.

Os entrevistados 4,11 e 13 sugerem que deve ser incluído como dimensão Oferecimento do ambiente propício, que envolveria questões de limpeza, climatização e conforto. 0 entrevistado 8 traz à tona a situação em que no processo educacional não existe uma preocupação dos docentes quanto ao desenvolvimento e busca de mercado para alguns alunos, ou seja, o planejamento de aula visando ao que o estudante busca.

Em observação às considerações apresentadas pelos entrevistados 4, 11 e 13 como novos elementos a serem inseridos na estrutura de avaliação da qualidade integrada proposta, verifica-se que, relativamente ao oferecimento de um ambiente propício que leva em consideração a infraestrutura, já se encontra contemplado nas dimensões Clientes e Controle de processos, não sendo assim necessário considerá-lo como uma nova dimensão de análise.

Em relação à sugestão do entrevistado 8, referente ao processo educacional, as mesmas considerações encontram-se contempladas na dimensão Controle de processos, na qual se discute a metodologia empregada no processo educacional, no caso de uma instituição de ensino.

De forma geral, é possível perceber que a qualidade ofertada, com base nas certificações ISO e PGQP, está de acordo com a qualidade demandada pelos clientes da instituição, o que demonstra que a utilização da ISO e do PGQP de maneira combinada, na instituição pesquisada, além de proporcionar a certificação do seu sistema de gestão e processos, indica também aos seus clientes que a instituição pode ser considerada como detentora de qualidade.

\section{CONSIDERAÇÕES FINAIS}

O presente trabalho teve por objetivo analisar a capacidade de uma instituição em atender aos requisitos de qualidade esperados por seus clientes, com base em certificações da qualidade ISO e PGQP. Dessa forma, amparando-se no referencial proposto e em suas referentes abordagens sobre a qualidade, como recomendado por autores, como Crosby (1984), Taguchi, Elsayed e Hsiang (1990), Drucker (1999) e Hargreaves, Zuanetti e Lee (2001), foi possível verificar a relevância e os elementos descritos para a obtenção de certificações da qualidade dos sistemas de gestão PGQP e ISSO; posteriormente, com os elementos de tais certificações analisados de maneira integrada, tornou-se possível desenvolver uma reunião de elementos embasada nas sobreposições, lacunas e relações entre eles, o que, por sua vez, permitiu a proposição de uma estrutura de análise da qualidade baseada nos elementos da ISO e PGQP. De posse de tal proposta, foi desenvolvido um instrumento de pesquisa, o qual foi aplicado a estudantes (clientes) de uma instituição de ensino na cidade de Pelotas/RS.

Nesse contexto, a maioria dos entrevistados indicou que todas as dimensões consideradas pelo PGQP e pela ISO são relevantes para a qualidade da instituição e, mesmo com a complexidade da definição do que é qualidade, foi possível perceber que os entrevistados compreendem a qualidade em similaridade com a abordagem aplicada no presente estudo.

A ênfase dos respondentes relativamente a questões institucionais vivenciadas por eles em seu cotidiano na instituição, como a limpeza, a infraestrutura, a climatização, colaboradores qualificados, o atendimento cordial e a organização, é capaz de demonstrar que as questões mais visíveis aos clientes são aquelas as quais eles, em geral, percebem como mais relevantes em relação à qualidade. Contudo, é relevante destacar que tais questões tornam-se mais bem atendidas quando elementos menos visíveis aos clientes, como liderança, estratégias, sociedade, controle de processos, resultados, inspeções e outros, ganham ênfase no desenvolvimento das atividades da instituição.

Por fim, considerando o convite à reflexão realizada no presente estudo, "é possível, por meio de certificações da qualidade, uma instituição de ensino obter a qualidade demandada por seus clientes?" e, com base nas considerações apresentadas, é possível constatar que a instituição pesquisada tornou-se 
capaz de atender à qualidade demandada pelos seus clientes a partir da qualidade ofertada, no caso, as certificações ISO e PGQP obtidas por ela.

De maneira geral, e observando uma provável relação direta entre a qualidade ofertada e a qualidade demandada, na instituição pesquisada, é relevante sugerir que busque, por meio do seu sistema de gestão e da estrutura proposta neste estudo, maneiras para atender aos requisitos das certificações ISO e PGQP de forma integrada. Em complemento, sugere-se ainda que a instituição torne-se capaz de obter maiores certificações, de Troféu Prata para Troféu Ouro do PGQP, e obter maiores pontuações na certificação ISO, considerando a menor quantidade possível de não conformidades e lacunas das certificações.

É importante ressaltar que as relações entre os elementos estabelecidos neste trabalho alteram-se ao longo do tempo, o que indica a importância de serem realizadas, no futuro, novas verificações sobre o tema; isso ocorre porque tanto os elementos abordados nas certificações quanto o conteúdo das expectativas de qualidade esperados pelos clientes podem modificar-se por influência de inúmeras questões, como políticas, sociais, econômicas e outras.

Mesmo com pouca quantidade de alunos pesquisados, visto o caráter qualitativo da pesquisa, a utilização apenas de elementos de certificações da qualidade ISO e PGQP, dado o enfoque proposto no estudo, e a verificação em uma instituição de ensino específica, em observação ao objetivo proposto, é possível constatar contribuições práticas e teóricas promovidas pela análise gerada pelo estudo conforme demonstrado; porém, algumas limitações devem ser apontadas.

Inicialmente, as dimensões abordadas em cada certificação seguem critérios próprios, desenvolvidos, mediante revisão teórica e empírica, pelos seus idealizadores. No entanto, o conjunto de dimensões propostas, conforme apresentado na revisão de literatura deste estudo, apresenta restrições relacionadas ao alcance destas, impostas pelos próprios modelos analisados, quer dizer, a análise da qualidade aqui proposta restringe-se aos elementos das certificações estudadas, não contemplando demais certificações ou abordagens divergentes.

A ampla verificação dos indicadores e fatores expostos nas certificações, como apresentado pelos seus idealizadores, faz com que sejam considerados válidos, tal como tratado nesta pesquisa. Porém, verificase que algumas certificações possuem vieses de aplicação em contextos específicos, que, apesar de serem empregados de forma generalizada, de acordo com a proposta de seus idealizadores, podem não possuir abrangência de suas aplicações em diferentes contextos.

Considerando que, para esta pesquisa qualitativa e exploratória, foram consultados apenas treze clientes da instituição, os resultados não podem ser generalizados, pois os dados são baseados nas percepções individuais dos entrevistados selecionados. Outro aspecto relevante está relacionado à excelente condição da instituição relativamente aos seus concorrentes, condição que pode afetar os resultados da pesquisa, impedindo, também, a generalização dos resultados.

A questão do método qualitativo escolhido para este trabalho, do mesmo modo, não permite a expansão dos resultados para outras instituições, dado que, nesta metodologia, se considera que os resultados estão relacionados ao contexto da instituição pesquisada e baseiam-se nas opiniões dos entrevistados. Assim, espera-se que este trabalho, ainda que tenha tido suas limitações, de alguma forma contribua para conhecimento acerca do tema, ainda pouco explorado no Brasil, e que estimule novas pesquisas na área de conhecimento em foco.

Dessa forma, uma verificação que parta da expectativa do cliente em relação à qualidade e, a partir dela, o desenvolvimento de dimensões a serem aplicadas na instituição, poderia ser considerada como uma possível pesquisa futura, uma vez que o enfoque deste trabalho partiu da instituição em relação aos clientes. Seria de grande valia também desenvolver esta pesquisa utilizando o método quantitativo, com o objetivo de verificar se a estrutura de análise proposta aplica-se às instituições, de forma mais ampla.

Por fim, o aprofundamento da maneira de influência das dimensões abordadas na instituição pesquisada, no que diz respeito aos seus clientes, poderia ampliar o entendimento sobre as relações existentes entre qualidade ofertada e a demandada, bem como ampliar as verificações a respeito da importância de cada dimensão para a qualidade de instituições de ensino. 


\section{QUALITY SUPPLIED AND DEMANDED: THE ISO AND PGQP CERTIFICATES OF QUALITY IN AN EDUCATIONAL INSTITUTION OF PELOTAS/RS}

\section{ABSTRACT}

This study aims to examine whether an educational institution is able to meet the requirements expected by its customers according to the ISO and PGQP quality certifications. This required revisiting theories and approaches to quality in its diverse applications.Then, an instrument to collect data based on the proposals and references studied was developed. Data collection was carried out through the use of interviews and data was subject to content analysis. Finally the results of the research and suggestions for improvements to the institution were presented. The research showed a relationship between the quality offered and the quality expected. Thus the requirements of ISO and PGQP certifications applied to the educational institution analysed showed to contemplate the quality requirements of its customers. In addition the research indicated that the maintenance of such certifications provide the possibility of expanding the service quality criteria expected by its customers.

Keywords: Quality management. Quality services. Quality at an institution of vocational education.

\section{REFERÊNCIAS}

BARDIN, Laurence. Análise de conteúdo. Rio de Janeiro, RJ: Edições 70, 1979.

CERQUEIRA, Jorge Pedreira; MARTINS, Márcia Copello. 0 sistema ISO 9000 na prática. São Paulo: Pioneira, 2008.

CROSBY, Philip. Qualidade é investimento. 3. ed. Rio de Janeiro: J. Olympio, 1984.

DRUCKER, Peter. Desafios gerenciais para o século XXI. São Paulo: Pioneira, 1999.

FUNEP. Encarte da Qualidade. São Paulo: FUNEP, 2012.

HARGREAVES, Lourdes; ZUANETTI, Rose; LEE, Renato. Qualidade em prestação de serviços. 2. ed. Rio de Janeiro: Senac Nacional, 2001.

MEZOMO, João Catarin. Educação e qualidade total: a escola volta às aulas. 2. ed. Petrópolis: Vozes, 1999.

OCDE. As escolas e a Qualidade. Portugal: Edições Asa, 1992.

PGQP. Encarte da qualidade. [2013a]. Disponível em: <http://www.mbc.org.br/mbc/pgqp/>. Acesso em: 5 dez. 2012.

PGQP. Critérios Compromisso com a Excelência. 6. ed. Porto Alegre: PGQP, 2013b.

ROSA, José Paulo da. Escola e qualidade: certificação ISO é importante? Porto Alegre: Nova Prova, 2008.

SAMPIERI, Roberto Hernandez; COLLADO, Carlos Fernández; LUCIO, Pilar Baptista. Metodologia de Pesquisa. 3. ed. São Paulo: McGraw Hill, 2006.

SPANBAUER, Stanley J. Um sistema de qualidade para educação: usando técnicas de qualidade e produtividade para salvar nossas escolas. Rio de Janeiro: Qualitymark, 1995.

TAGUCHI, Genichi; ELSAYED, Ahmed; HSIANG, Thomas. Engenharia de qualidade em sistema de produção. São Paulo: McGraw Hill, 1990. 
VIEIRA, Marcelo Milano Falcão; CARVALHO, Cristina Amélia. Qualidade e objetivos: implicações teóricas e metodológicas para a análise das organizações. In: VIEIRA, Marcelo Milano Falcão; OLIVEIRA. Lúcia Maria Barbosa. (Org.). Administração contemporânea: perspectivas estratégicas. São Paulo: Atlas, 1999. p. 121-147.

WILSON, David. A strategy of change: concepts and controversies in the managment of change. London: Roytledge, 1992. 